Agro-Science Journal of Tropical Agriculture, Food, Environment and Extension Volume 11 Number 1 Januarv 2012 nn 16 - 20

ISSN 1119-7455

\title{
ARRHENIUS AND ABSOLUTE REACTION RATE MODELS FOR THERMODYNAMIC CHARACTERIZATION OF LINAMARASE (B- GLUCOSIDASE) USING LINAMARIN SUBSTRATE
}

\author{
Kwagh-har Ikya ${ }^{1}$ J. Ariahu' ${ }^{1}$ C.C., and Ayatse ${ }^{2}$ J. O. I. \\ Department of Food Science and Technology, University of Agriculture, Makurdi. \\ ${ }^{2}$ FederalUniversity Dutsin-Ma, Katsina State \\ Corresponding Author: Julius Kwagh-har Ikya, P. M. B. 2373, Makurdi, Benue State,
}

\begin{abstract}
Thermodynamic characterization of linamarase ( $\beta$-glucosidase)influenced by linamarin substrate purification, $\mathrm{pH}$ and temperature were investigated. In the study, recombinant Saccharomyces cerevisiae cells at the stationary phase of growth were recovered, homogenized and centrifuged to

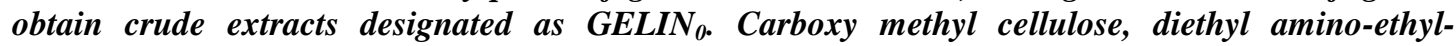
sephadex and diethyl amino-ethyl-cellulose were used to purify the crude extracts resulting in $G_{E L I N}$, GELIN $_{2}$ and GELIN 3 , respectively. Commercial native linamarase (CNLIN) was purchased and used as control. The ability of the GELIN extracts(B-glucosidase) and the commercial native linamarase (CNLIN) to hydrolyse cyanogenic glucosides was challenged using linamarin extracted from cassava as substrates. Degradation of linamarin was evaluated at optimum pH 6.8 using $a 4 \times 6 \times 8$ between and within factorial design comprising of 4 enzyme types $\left.\left(\text { GELIN }_{0}, \text { GELIN }_{1}, \text { GELIN }_{2} \text { and GELIN }\right)_{3}\right)$, and 6 temperatures $\left(25,27,29,31,33,35{ }^{\circ} \mathrm{C}\right.$, respectively) and 8 time intervals $(0,10,20,30,40,50,60$ and $70 \mathrm{~min}$.). Data obtained from residual hydrocyanic acid with time were fitted with zero, first and second order kinetics, respectively, to determine the best fit order (based on $r^{2}$ and linearity). Arrhenius and absolute reaction rate models were applied to obtain activation energies $\left(E_{a}\right)$, frequency factor $\left(K_{0}\right)$ and enthalpy $\left(\Delta H^{*}\right)$, entropy $\left(\Delta S^{\#}\right)$, respectively, that characterized the reactions. The results indicated that the degradation of linamarin by GELIN at the optimum pH 6.8 was best described by first order kinetics, Arrhenius and absolute reaction rate models showing high coefficient of linear regression $\left(r^{2}>0.996\right)$ with reaction rate constant increasing from $0.0252-0.0923 \mathrm{~min}^{-1}$ with enzyme purification ranging for GELIN $_{0}-$ GELIN $_{3}$. Frequency factor $\left(K_{0}\right), E_{a}, \Delta H^{\#}$ and $\Delta S^{\#}$ values decreased with enzyme purification. Activation energy $\left(E_{a}\right)$ values for the degradation of linamarin $\left(G E L I N_{0}-G E L I N_{3}\right)$ ranged from 60.9 to $91.7 \mathrm{~kJ} / \mathrm{mol}$. Enthalpy values varied from 58 to $89 \mathrm{~kJ} / \mathrm{mol}$ while $\Delta \mathrm{S}^{\#}$ values varied from -92.8 to $4.1 \mathrm{~J} / \mathrm{mol}$. deg.) indicating spontaneous and irreversible degradation reactions which suggest a possible use of the purified linamarase (B-glucosidase) in detoxification process for foods containing linamarin.
\end{abstract}

Keywords: purified linamarase, rate models, linamarin, Saccharomyces cerevisiae, cassava

\section{INTRODUCTION}

Previous studies (Canjura et al., 1991; Krug et al., 1976; Rhim et al., 1990) have shown that both activation enthalpy $\left(\Delta H^{\#}\right)$, entropy $\left(\Delta S^{\#}\right)$, energy $\left(E_{a}\right)$ and frequency factor $\left(k_{o}\right)$ usually exhibited marked thermodynamics effect on degradation reactions in which increases in $\Delta \mathrm{H}^{\#}$ was accompanied by increase in $\Delta \mathrm{S}^{\#}$. The degradation reactions are usually influenced by environmental conditions especially temperature with resultant thermodynamics relationships which can be useful for predictive purposes in controlled fermentation and degradation of toxic compounds in foods. Arrhenius and absolute reaction rate models can be applied for thermodynamic characterization of enzymes employed in controlled fermentation of foods containing cyanogenic glucosides. Errors may sometimes accompany these predictions. Actually, the Arrhenius equation in itself is an approximation of the true temperature dependency model (Rhim et al., 1990). Secondly, computational errors involved in 
calculating apparent kinetic parameters $\left(\Delta \mathrm{H},{ }^{\#}\right.$ $\Delta \mathrm{S}^{\#}, \mathrm{E}_{\mathrm{a}}$, and $\mathrm{k}_{\mathrm{o}}$ ) are propagated throughout the calculation procedure. The apparent kinetic parameters are derived quantities, removed from the experiment by a number of steps of computation, and their values are not obtained independently, but are computed from a single equation. To test the validity of the Arrhenius and absolute reaction rate models for the characterization of enzymes such as linamarase used for the degradation of linamarin regression analysis, as described by Canjura et al., (1991). Was use

\section{MATERIALS AND METHODS}

Materials:

Enzyme samples: Commercial Native Linamarase (CNLIN) used as the control for this study was purchased from Sigma Co. Lousina, USA. $\beta$-glucosidase (GELIN) was obtained from the Department of Food Science and Technology, University of Agriculture, Makurdi. Crude GELIN extractfrom Saccharomyces cerevisiae $\left(\mathrm{GELIN}_{0}\right)$ was further purified using Carboxy methyl cellulose $\left(\mathrm{GELIN}_{1}\right)$, Diethylamino-ethyl- sephadex $\left(\mathrm{GELIN}_{2}\right)$ and Diethylamino-ethyl-cellulose $\left(\mathrm{GELIN}_{3}\right)$

Production of Linamarin (Substrate): Linamarin (100 g) was extracted from about 2 $\mathrm{kg}$ tubers of the bitter wild cassava (Manihot esculenta pohr) variety TSM-TRF-2005035 obtained from Tse-Akaa Village, Mbalagh, Makurdi, Benue State, Nigeria and produced using the method described by Ikediobi et al., (1985).

Linamarin: One year old cassava tubers were harvested, washed with tap water and promptly frozen overnight at $-10{ }^{\circ} \mathrm{C}$. About $800 \mathrm{~g}$ of frozen cassava parenchyma tissues were sliced with stainless steel knives and homogenized with $160 \mathrm{ml}$ of chilled $0.1 \mathrm{M}$ phosphoric acid solution. The resultant slurriy was filtered rapidly using glass wool and the filtrate centrifuged $(1000 \mathrm{rpm})$ for $5 \mathrm{~min}$. The resultant filtrate was centrifuged at $5000 \mathrm{x}$ g for $5 \mathrm{~min}$ and the supernatant adjusted to $\mathrm{pH} 8.0$ followed by re-centrifugation at $5000 \times \mathrm{g}$ for $8 \mathrm{mins}$. After decanting, the solid residue was air-dried to obtain about $0.82 \mathrm{~g}$ of white substrate (mp.143 $\left.{ }^{\circ} \mathrm{C}\right)$. This was stored at $4{ }^{\circ} \mathrm{C}$ and subsequently used for characterization of activity kinetic profiles.
Buffer Solutions and Analytical grade Reagents: Buffer solutions and reagents were prepared for the study using standard methods.

Kinetic studies: The ability of Commercial Native Linamarase (CNLIN) purchased as control and the GELIN extracts from Saccharomyces cerevisiae to hydrolyse cassava linamarin to hydrocyanic acid (HCN) released within a fixed time was challenged. Spectrophotometric method was used for the estimation of hydrocyanic acid ( $\mathrm{HCN})$ released within a fixed time as described by Onyike et al. (2001).

\section{Thermodynamic studie Activated complex approach}

The temperature dependency of linamarase degradation of the substrates was verified using the Arrhenius (Eqn.1) and Absolute reaction (Eqn.2) models, respectively.

\section{$\ln K=\ln K_{0}-E_{a} / R(1 / T)$}

(Eqn. 1)

where $E_{a}$ is activation energy, $\mathrm{R}$ is the universal gas constant $\left(0.008314 \mathrm{~kJ} / \mathrm{mole}{ }^{\circ} \mathrm{C}\right), \quad \mathrm{T}$ is absolute temperature and $\mathrm{k}_{\mathrm{o}}$ is the frequency factor. Activation energy and $\mathrm{k}_{\mathrm{o}}$ values were determined from slopes and intercepts, respectively, of lines generated by regressing the $\ln \mathrm{k}$ versus $1 / \mathrm{T}$ by use of least square linear regression as described by Ariahu and Ogunsua (2000).

Regressional analysis of $\ln k$ versus inverse absolute temperature for GELIN extract degradation of linamarin. Absolute Rate theory approach

$\ln \mathrm{k} / \mathrm{T}=\left(\mathrm{K}_{\mathrm{s}} / \mathrm{h}_{\mathrm{c}}+\Delta \mathrm{S}^{\#} / \mathrm{R}\right)-\Delta \mathrm{H}^{\#} / \mathrm{R}(1 / \mathrm{T}) \quad($ Eqn. 2$)$ where $K_{s}$ and $h_{c}$ are Boltzmann and Planck constants, respectively. From the slopes and intercepts of the lines obtained by regressing $\ln$ $\mathrm{k} / \mathrm{T}$ versus $1 / \mathrm{T}$ relationship, $\Delta \mathrm{H}^{\#}$ (activation enthalpy) and $\Delta S^{\#}$ (activation entropy), respectively, were evaluated.

\section{Statistical Analysis}

The least square linear regression analysis of the kinetics thermodynamics (Arrhenius and transition state model parameters) were calculated as described by Van-Boekel (1996) and Gupta (1979). 
Table I: Arrhenius Kinetic Parameters for Degradation of Linamarin by GELIN at pH 6.8

\begin{tabular}{|c|c|c|c|c|}
\hline & Substrate & Regression & Enzyme type & Parameter \\
\hline & GELIN $_{0}$ & GELIN $_{1}$ & GELIN $_{2}$ & GELIN $_{3}$ \\
\hline $\mathrm{n}$ & 6 & 6 & 6 & 6 \\
\hline$r^{2}$ & 0.993 & 0.990 & 0.996 & 0.994 \\
\hline \multirow[t]{2}{*}{ Linamarin } & Intercept & 30.9965 & 28.9038 & 25.9412 \\
\hline & $2.9 \times 10^{13}$ & $3.6 \times 10^{12}$ & $1.8 \times 10^{11}$ & $\begin{array}{l}19.3405 \\
2.5 \times 10\end{array}$ \\
\hline \multicolumn{5}{|c|}{$\approx \mathrm{k}_{\mathrm{o}}\left(\min ^{-1}\right)$} \\
\hline Gradient & $\begin{array}{l}-11032.66 \\
91.7\end{array}$ & $\begin{array}{l}-10224.45 \\
85\end{array}$ & -9341.34 & $\begin{array}{c}-7325.77 \\
60.9\end{array}$ \\
\hline
\end{tabular}

$\mathrm{n}=$ number of points, $\mathrm{r}^{2}=$ coefficient of regression, $\mathrm{k}_{\mathrm{o}}=$ frequency factor, $\mathrm{E}_{\mathrm{a}}=$ activation en energy

GELIN $_{0}=$ Crude linamarase, GELIN ${ }_{1}=1^{\text {st }}$ degree of purification using carboxy-methyl cellulose $(\mathrm{CMC})$,

GELIN $_{2}=2^{\text {nd }}$ degree of purification using diethyl amino ethyl-sephadex (DEAE-sephadex)

GELIN $_{3}=3^{\text {rd }}$ degree of purification using diethyl amino ethyl-cellulose (DEAE-cellulose)

Table 2: Absolute Rate Parameters for GELIN Degradation of Linamarin at pH 6.8

\begin{tabular}{|c|c|c|c|c|}
\hline \multicolumn{2}{|c|}{ Regression } & \multicolumn{3}{|c|}{ Enzyme type } \\
\hline Substrate GELIN $_{3}$ & Parameter & GELIN $_{0}$ & GELIN $_{1}$ & GELIN $_{2}$ \\
\hline $\mathrm{N}$ & 6 & 6 & 6 & 6 \\
\hline$r^{2}$ & 0.950 & 0.935 & 0.985 & 0.990 \\
\hline Intercept & 24.2582 & 22.1661 & 19.2046 & 12.6038 \\
\hline Linamarin & & -13.3 & -37.9 & -92.8 \\
\hline & $\stackrel{\sim}{*} \Delta \mathrm{S}^{\#}$ (J/deg.mol). 4.1 & & & \\
\hline Gradient & $89^{-10722.19}$ & $\begin{array}{l}-9914.17 \\
82\end{array}$ & $\begin{array}{l}-9031.38 \\
75\end{array}$ & $58^{-7015.77}$ \\
\hline
\end{tabular}

$\therefore \Delta \mathrm{H}^{\#}(\mathrm{~kJ} / \mathrm{mol}$.)

$\Delta \mathrm{H}^{\#}=$ activation enthalpy, $\Delta \mathrm{S}^{\#}=$ activation entropy, $\mathrm{n}=$ number of points, $\mathrm{r}^{2}=$ coefficient of regression GELIN $_{0}=$ Crude linamarase, GELIN ${ }_{1}=1^{\text {st }}$ degree of purification using carboxy-methyl cellulose (CMC),

GELIN $_{2}=2^{\text {nd }}$ degree of purification using diethyl amino ethyl-sephadex (DEAE-sephadex)

GELIN $_{3}=3^{\text {rd }}$ degree of purification using diethyl amino ethyl-cellulose (DEAE-cellulose)

\section{RESULTS AND DISCUSSION}

Zero and second order kinetics fitted poorly $\left(\mathrm{r}^{2} \leq\right.$ 0.901) and were not considered in the thermodynamics characterization of linamarase for the degradation of linamarin. Reaction rate constant K-values obtained from first order kinetics fitted best with high coefficient of linear regression values $\left(r^{2}>0.996\right)$.

\section{Activated complex approach:}

Plots of $\ln \mathrm{k}$ versus inverse absolute temperature for the GELIN degradation of linamarin were linear and temperature dependent. The regression parameters and derivatives for the Arrhenius relationships are provided in Table I. Activation energy $(\mathrm{kJ} / \mathrm{mol})$ ranged from 60.9 to 91.7 (linamarin). Both frequency factor and activation energy were higher for the crude enzyme and decreased with degree of purification. The mean activation energy for degradation of linamarin was 78.8
$\mathrm{kJ} / \mathrm{mol}$. The frequency factors $\left(\mathrm{k}_{\mathrm{o}}\right)$ increased with enzyme purity from GELIN G $_{0}$ to GELIN 3 , corresponding to $\mathrm{k}_{\mathrm{o}}$ of $2.9 \times 10^{13}$ to $2.5 \times 10^{8} \mathrm{~min}^{-}$ 1 . The frequency factor $\left(\mathrm{k}_{\mathrm{o}}\right)$ is a measure of probability of effective collision and interaction of substrates with enzyme molecules for products formation. The high correlation coefficient $\mathrm{r}^{2}$ values (0.993-0.994) indicated that the Arrhenius model adequately characterized the temperature dependency of the GELIN degradation of linamarin. Arrhenius model was empirically derived to describe the temperature dependence of simple chemical and enzyme catalyzed reactions. The activation energy can be seen as the energy barrier that reacting species need to cross in order to be able to react. Higher activation energy implies that a smaller temperature change is required to degrade a specific compound more rapidly (Ariahu et al., 1997). The $E_{a}$-value is a measure of sensitivity and dependence of the substrates degradation on 
temperature. Larger magnitude of $\mathrm{E}_{\mathrm{a}}$ is associated with higher temperature dependency. The cyanogenic glucosides are, therefore, more sensitive to temperature at $\mathrm{pH} 6.8$ and lower enzyme purity. This implies that a small change in temperature would result in a larger change in the rate of degradation of the cyanogenic glucosides at the optimum $\mathrm{pH}$ by the crude enzyme. The changes in $\mathrm{E}_{\mathrm{a}}$ were accompanied by parallel increase of the collision factors $\left(\mathrm{k}_{\mathrm{o}}\right)$. According to Speroni et al. (1985) and also Ariahu and Ogunsua (2000), whenever the $E_{a}$ and $\mathrm{k}_{\mathrm{o}}$ values differ between two systems, it is tempting to imply dissimilarity in mechanism of degradation reactions. In this present study, the $\mathrm{E}_{\mathrm{a}}$ or $\mathrm{k}_{\mathrm{o}}$ - values differed significantly $(\mathrm{p}<0.05)$ between enzymes investigated. However, it must be pointed out that the frequency factors were determined by extrapolation to values well outside the range of temperatures used experimentally. This could explain the reason for minor changes in the $E_{a}$ values resulting in substantial changes in $\mathrm{k}_{\mathrm{o}}$-values. The $\mathrm{E}_{\mathrm{a}}$ values observed in the present study are within the values of $21-120 \mathrm{~kJ} / \mathrm{mol}$ reported for enzyme catalyzed reactions (Rhim et al., 1990; Taokis and Labuza 1989)

\section{Absolute Rate theory approach.}

The parameters and derivatives for the absolute rate description of linamarin degradation by the GELIN at $\mathrm{pH} 6.8$ are provided in Table II. The enthalpy of activation $\left(\Delta \mathrm{H}^{\#}\right)$ for the degradation of the substrates, as influenced by enzyme purification, varied for linamarin from 58 to $89 \mathrm{~kJ} / \mathrm{mol}$. The $\Delta \mathrm{H}^{\#}$ values decreased with increase in degree of enzyme purification. The entropy of activation $\left(\Delta S^{\#}\right)$ also decreased with enzyme purification and ranged from -92.8 to $4.1 \mathrm{~J} / \mathrm{mol}$.deg (linamarin). The coefficients of regression $\left(\mathrm{r}^{2}\right)$ were $\geq 0.950$ and the entropy of activation $\left(\Delta S^{\#}\right)$ decreased with enzyme purity. The high correlation coefficient $\left(r^{2} \geq 0.990\right)$ suggests adequate fit of the transition state model in describing and characterizing the enzyme degradation of linamarin. Corresponding increases in enthalpy and entropy values suggest greater sensitivity of the reaction to temperature, enzyme purity and $\mathrm{pH} 6.8$. The $\Delta \mathrm{H}^{\#}$-value is a measure of the energy barrier that must be overcome by the reacting species. According to Atkins (1986), $\Delta H^{\#}$ value is an indication of the internal energy of the activated complex formed just before the transition state is reached. This value is related to the strength of the bonds which are broken and made in the formation of the transition state from the reactants. Entropy is related to how many molecules with the appropriate energy can actually react. The $\Delta S^{\#}$ being non zero indicated that the $\beta$-glucosidase degradation of the cyanogenic glucosides was spontaneous and irreversible. The negative values of $\Delta S^{\#}$ indicated an increase in structural order of molecules in the activated complex. Higher values suggest increased degree of freedom of the reacting species, higher degree of disorderliness and less probability of degradation of the substrates. The value of entropy $\left(\Delta S^{\#}\right)$ includes the degree of stearic and orientation requirements and also solvent effects. Hence, the absolute reaction model provides a better insight into the roles of these factors in the degradation of the cyanogenic glucosides than the less definitive probability approach of the collision theory. As a result of the empirical nature of the Arrhenius model, it was proposed that absolute reaction rate model be applied in the analysis of food quality degradation rate data (Ariahu \& Ogunsua, 2000). According to Keresztessy et al. (2001), $\beta$-glucosidases catalyse the hydrolysis of $\beta$-glucosidic linkages of conjugated monoglycosides. The enzyme used a common double-displacement mechanism involving two active site carboxylates to release their saccharide product with net retention of configuration of the sugar ring on the newly exposed anomeric centre. An acid/base catalytic group exists for protonation of the gylcosidic oxygen to release the aglycone. A nucleophile catalyst stabilizes an oxocarbenium-ion-like transition state, which collapses into a covalent glycosyl-enzyme intermediate. Therefore, if the "lock-and-key" model for enzyme catalysis as reported by Laidler (1987) is assumed, then decreases in entropy will imply an orderly arrangement of the reacting species to fit into active sites and would favour degradation of the cyanogenic glucosides. Lower entropy implies that the degree of freedom of the reacting species reduced with purification thereby reducing the distances and energy to get to the active sites. Impurities on the other hand provide increased disorderliness and higher degree of freedom for the reacting species with less probability of reaching the enzyme active sites for formation of activated complexes. Again, blockage of the enzyme's active sites by the impurities resulted in higher $\mathrm{E}_{\mathrm{a}}$ and $\Delta \mathrm{H}^{\#}$ values, hence higher energy requirements to overcome the hindrance and resistance to formation of activated complexes. The mean $\Delta \mathrm{S}^{\#}(\mathrm{~J} / \mathrm{mol} . \mathrm{deg})$ and $\Delta \mathrm{H}^{\#}(\mathrm{~kJ} / \mathrm{mol})$ were, respectively, -35.0 and 76.0 for linamarin degradation. Therefore, the order of degradation of linamarin by the linamarase is GELIN 0 , $>$ GELIN $_{1}>$ GELIN $_{2}>$ and GELIN $_{3}$ 


\section{CONCLUSION}

The degradation of linamarin by GELIN obeyed first order reaction kinetics and was influenced by environmental conditions, especially temperature $\left(25-35^{\circ} \mathrm{C}\right)$. The temperature dependency of the enzymic degradation of linamarin by GELIN can be adequately described using the Arrhenius, and absolute rate models. The thermodynamics relationships can be useful for predictive purposes in controlled fermentation and degradation of linamarin in foods.

\section{REFERENCES}

Ariahu, C. C., Adekunle, D. E. and Nkpa, N. N. (1997). Kinetics of heat/enzyme degradation of ascorbic acid in fluted pumpkin (Telfairia occidentalis) leaves. Journal of Food Processing and Preservation 21:21-32.

Ariahu, C. C. and Ogunsua, A. O. (2000).Thermal degradation kinetics of thiamine in periwincle based formulated low acidity foods. Int.J. Food Sci. Technol. 35:315-321

Atkins, P. W. (1986). Physical chemistry. 3rd ed. Oxford: Oxford University Press.

Canjura, F. L., Schwartz, S. J. and Nunes, R. V. (1991). Degradation kinetics of chlorophylls and chlorophyllides. J. Food Science 56(6):1639-1643.

Gupta, C. B. (1979). An Introduction to Statistical Methods. $8^{\text {th }}$ Edition. New Delhi. G. Vikas Publishing House, PVT. p 424-480.

Ikediobi, C. O., Ogundu, E. C. and Ukoha, A. I. (1985). Production of linamarase by Aspergillus sydowi and Fusarium equiseti. Process Biochemistry 20, 99102.

Keresztessy, Z. S., Brown, K., Dunn, M. A. and Hughes, M. A. (2001). Identification of Active site Residue in the cyanogenic $\beta$-glucosidase from cassava by site -directed mutagenesis. Biochem. J. 353:199205
Krug, R. R., Hunter, W. G. and Grieger, R. A. (1976). Enthalpy- Entropy compensation. Some fundamental statistical problems associated with the analysis of Van't Hoff and Arrhenius data. J. Phys. Chem. 80(21): 2335-2341.

Laidler, K. J. (1987). The chemical kinetics of enzyme action, $2^{\text {nd }}$ edition. NewYork : Oxford

Onyike, E., Ukoha, A. and Ikediobi, C. O.(2001). Isolation and Characterization of Linamarase from Dried Cassava (Manihot esculenta Crantz) Cortex. Nig. J. Biochem. and Mol. Biol. 6(3): 739785.

Rhim, J. W., Jonnes, V. A. and Swartzel, K. R. (1990). Kinetic compensation effect in the heat denaturation of whey protein. J. Food Science 55 (2): 589-592.

Speroni, J. J., Sastry, S. K. and Bechaman, R. B. (1985). Thermal degradation kinetics of argaritine in model systems and argaritine retention in canned mushrooms. J. Food Science 50: 13061311.

Taokis, H. and Labuza, T.P. (1989). Acceptability of time temperature indicators as life monitors of food products. J. Food Science 54(4): 788 798.

Van-Boekel, M.A. J.S. (1996). Statistical aspect of kinetic modeling for Food Science problems. J. Food Science 61(3): 477485 